\title{
THE
}

\section{Modeling multiple health behaviors and general health}

Kelsey Elise Ufholz

Lisa L. Harlow

University of Rhode Island, Iharlow@uri.edu

Follow this and additional works at: https://digitalcommons.uri.edu/psy_facpubs

The University of Rhode Island Faculty have made this article openly available.

Please let us know how Open Access to this research benefits you.

This is a pre-publication author manuscript of the final, published article.

Terms of Use

This article is made available under the terms and conditions applicable towards Open Access

Policy Articles, as set forth in our Terms of Use.

\section{Citation/Publisher Attribution}

Ufholz, K. E., \& Harlow, L. L. (2017). Modeling multiple health behaviors and general health. Preventive Medicine, 105, 127-134. https://doi.org/10.1016/j.ypmed.2017.08.003

Available at: https://doi.org/10.1016/j.ypmed.2017.08.003 
RUNNINING HEAD: HEALTH BEHAVIOR MODELING

This is not the copy of record. It is a preprint version of: Ufholz, K. E., \& Harlow, L. L. (2017). Modeling multiple health behaviors and general health. Preventive Medicine, 105, 127-134. https://doi.org/10.1016/j.ypmed.2017.08.003

\title{
Modeling Multiple Health Behaviors and General Health
}

\author{
Kelsey EliseUfholz ${ }^{1}$ and Lisa L. Harlow
}

University of Rhode Island

\begin{abstract}
Multiple Health Behavior Change assumes health behaviors are related to one another, although research evidence is mixed. More research is needed to understand which behaviors are most closely related and how they collectively predict health. Principle component analysis and structural equation modeling were used to establish a model showing relations between health behaviors, including fruit/vegetable consumption, aerobic and strength exercise, alcohol intake, and smoking, and how these behaviors relate to general physical and mental health functioning in a large, national sample. Although health behaviors were found to coalesce into a health-promoting factor of diet, and exercise, a better overall model fit was found when all behaviors were modeled as separate independent variables. Results suggest that health behaviors relate to one another in complex ways, with perceived health status serving as a mediating variable between specific health behaviors and a factor of physical and mental health. Future research should further investigate how other health behaviors relate to perceptions and overall health, especially among subpopulations.
\end{abstract}

Keywords: health behavior; primary prevention; public health; models, statistical

\footnotetext{
${ }^{1}$ Now at the Grand Forks Human Nutrition Research Center, US Department of AgricultureAgricultural Research Service, Grand Forks, North Dakota.
}

\section{Acknowledgements}

The authors would like to thank Joseph Rossi for his help in preparation of this manuscript. Lisa Harlow also extends thanks to the National Institutes of Health grant G20RR030883. 
RUNNINING HEAD: HEALTH BEHAVIOR MODELING

\section{Modeling Multiple Health Behaviors and General Health}

The United States' current disease burden involves chronic illnesses, such as cardiovascular illness, cancer, and diabetes (Mathers \& Loncar, 2006). Healthy behaviors can decrease the risk of these illnesses (Blair et al., 1996; National Research Council, 1989). Good physical and mental health is aided by eating fruits and vegetables, exercising regularly, avoiding smoking, and responsible alcohol intake (USHHS \& USDA, 2015). Evidence suggests multiple healthy behaviors further decrease health risk overall (Baer et al., 2010; Berrigan et al., 2003).

Unfortunately, few American adults meet guidelines regarding fruit intake (13.1\%), vegetable intake (8.9\%) (CDC, 2015a), and exercise (20.9\%) (CDC, 2017; USDHHS, 1991). Moreover, 15.1\% of adults smoke (CDC, 2017) and 23.4\% abuse alcohol (CDC, 2017). Further, these health behaviors are the leading causes of death among American adults (Mokdad et al., 2004). Encouraging healthier diets, more physical activity, smoking cessation, and responsible alcohol consumption are major public health priorities.

Theory. Health behavior change emphasizes individual behaviors. However, research is now considering ntervention on multiple behaviors. Because multiple health behavior change (MHBC) research is developing, many questions remain (Noar et al., 2008; Prochaska, Spring \& Nigg, 2008), including which behaviors to treat together (Spring, Moller \& Coons, 2012). Certain behaviors, such as diet and exercise, tend towards co-action (Mawditt et al., 2016). Lippke et al., (2012) found health behaviors tended to assemble into a health-enhancing or a health-reducing cluster. Theoretically, such clustered behaviors would show the greatest co-action; MHBC interventions may maximize their impact by using this synergy (Paiva et al., 2012).

The best behaviors for MHBC interventions often focus around a theme of energy balance (Paiva et al., 2012). Other research suggests that participants choose their behavioral (Allgrante et al., 2008). Since behavioral combination efficacy is a fundamental aspect of MHBC, more research is clearly needed. Chosen behaviors must also demonstrate strong effect on physical and mental health.

Health behaviors may not be as linked as theorized. Newsom et al. (2005) examined smoking, exercise, alcohol consumption, and diet behaviors within several North American public health datasets and suggested that shared variance is miniscule. Therefore, MHBC interventions are conceptually unfounded. This suggests associations between health behaviors and overall health should be examined.

Our research examined links between health behaviors, and whether these behaviors were collectively predictive of good health, using a large, nationally representative sample. If the health behaviors are significantly related it suggests sufficient co-action for a joint intervention. If the health behaviors were relatively independent, it implies behaviors may be addressed separately. Specifically, we examined whether diet, exercise, smoking, and alcohol consumption would form one of two health 
RUNNINING HEAD: HEALTH BEHAVIOR MODELING

behavior factors, one promoting good health and one reducing good health, consistent with Lippke et al. (2012). An alternate model assessed whether health behaviors acted as separate variables. In each model, the health behaviors, were hypothesized to relate to an outcome factor representing physical and mental health.

\section{Methods}

Dataset. This study analyzed data from the Behavioral Risk Factor Surveillance System (BRFSS) (CDC, 2013). The BRFSS is an annual telephone survey assesses health behaviors among adults from the United States' civilian, non-institutionalized population. The BRFSS utilizes a complex, multistage sampling design. Certain variables were collected by all states and others were optional (see Table 1). Data from 2011 were analyzed for the current study (Total $\mathrm{N}=506,467$ ). The BRFSS has results comparable to other health-related self-report surveys, demonstrating high reliability and validity (Pierannunzi et al., 2013).

Variables. The endogenous (dependent) factor in our proposed model corresponds to general physical and mental health (Overall Health) with variables of perceived general health status (Excellent, Very Good, Good, Fair, Poor) (Perchlth), number of days (0-30) in past month with good physical health (Physhlth), number of days (0-30) in the past month with good mental health (Menhlth), and number of days (0-30) in the past month when a person could perform normal activities, free of health-related problems (Activity). Health behavior was divided into two exogenous (independent) factors, those thought to enhance health (Health Enhance) and those thought to reduce health (Health Reduce) (see Figure 1). The behaviors cigarette smoking, fruit and vegetable consumption, aerobic and strength exercise, and alcohol consumption were selected based on their association with health, and to replicate work by Newsom et al. (2005) and Mawditt et al (2016).

Physical activity was calculated by asking participants whether they engaged in leisure-time physical activity in the past month, and if so which activities, how often, and for how long. Participants were asked how often they performed exercises designed to strengthen muscles. Based on responses, participants were classified by how well they met Physical Activity Guidelines of 150 minutes of moderate-intensity aerobic exercise per week (CDC 2015b; USDA, 2016) (zero minutes, between one and 149 minutes, or 150 or more minutes). Strength-enhancing exercise was classified as meeting vs. not meeting recommended guidelines of two weekly strength-enhancing exercise sessions.

Fruit and vegetable intake was calculated by asking participants how often in the past month, they consumed fruit or vegetables belonging to certain categories such as $100 \%$ fruit juice, leafy green vegetables, beans etc. Final scores were converted to servings per day and summed to total fruit intake per day (Fruit), and total vegetable intake per day (Veg). Following CDC recommendations, fruit responses 
RUNNINING HEAD: HEALTH BEHAVIOR MODELING

exceeding 16 servings per day and vegetable responses exceeding 23 servings per day were classified as too extreme and excluded.

Health-reducing factors corresponded to current smoking status, binge drinking status, and average alcoholic drinks per day. Participants were asked if they had smoked 100 cigarettes throughout their entire life, how long since they had last smoked, and whether they smoked every day or only some days. Participants were classified as never, former, some days, or everyday smokers (Smoke). Participants were asked how many days in the past month they consumed alcohol, how many drinks per day on average, and largest number of drinks on a given occasion. Average number of drinks per day was calculated (Drink), as well as binge drinking status (not a binge drinker vs. binge drinker) (Binge). Similar to fruit/vegetable responses, some participants gave unrealistically high answers; values exceeding 16, double the average number of drinks per day for binge drinkers $(M=7.7)$ (Kanny et al., 2013), were excluded. All variables were self-reported. Answers coded as "I don't know" or refusal to answer were coded missing.

Preliminary Analyses. The initial step involved variable selection. As we examined an existing dataset, only theoretically relevant variables with less than $50 \%$ data missing were considered. Basic descriptives including mean, standard deviation, skewness, kurtosis, and bivariate correlations were examined with SPSS 19.0. Variables were coded with higher scores indicating a greater amount. This usually equated to more positive behaviors, with the exception of drinks/day, binge drinking, and smoking status, in which higher scores indicated binge drinking status, and a greater number of drinks or cigarettes per day. Variables showing skewness exceeding $|3.0|$ were log base 10 transformed (see Table 2).

Following variable selection, hypothesized factors were examined with SPSS 19. Principle component analysis (PCA) investigated a three-factor model (i.e., Health Enhance, Health Reduce and Overall Health) with each variable loading on their expected factor. Factor structure was assessed using percentage of variance accounted for, eigenvalues exceeding |1.0|, a scree plot (Cattell, 1966), and theoretical relevance (Harlow, 2014). Variables were preferred to have loadings $>|0.30|$. Because the three factors were anticipated to be correlated, Promax rotation was used.

Major Analyses. Following PCA confirmation, the hypothesized factors were examined via structural equation modeling (SEM) with EQS 6.2 (Bentler, 2006). The hypothesized model with two exogenous factors was compared to a theoretical alternative model with each exogenous variable related individually to the endogenous factor (Beran \& Violato, 2010; Kline, 2016). Model fit was assessed via several methods (Jackson et al., 2009; McDonald \& Ho, 2002). Chi-square tests initially assessed overall model fit. Additional model fit indices included root mean square error of approximation (RMSEA) with its $90 \%$ confidence interval, the Bentler Comparative Fit Index (CFI), and the McDonald Fit Index (MFI). 
RUNNINING HEAD: HEALTH BEHAVIOR MODELING

In each model, the pathway of one variable per factor was constrained to 1.0. Sufficient overall fit corresponded to RMSEA <.06, and CFI and MFI $\geq .90$ (Harlow, 2014; Hu \& Bentler, 1999). LaGrange and Wald tests determined if any parameters should be added or deleted, respectively. Comparisons between competing models were determined by superior overall fit indices, relative fit indices of the Akaike Information Criterion (AIC), theoretical relevance, and parsimony, with preference for simpler models. Because no states provided complete data, a considerable amount was missing. Missing data procedures were not appropriate because data was not missing at random (Bentler, 2006). Therefore, as model confirmation and to ensure better validity, the final nationally representative model was repeated in four individual states randomly selected from the US Census Bureau's four regions (South, Georgia; Northeast, Massachusetts; Midwest, Minnesota; West, Utah) (see Appendix), both individually and collectively via multisample invariance testing.

\section{Results}

Preliminary Analyses. Three factors explained 52.27\% of the variance in the variables. The four variables representing general physical and mental health all loaded strongly on the hypothesized factor of Overall Health (Table 3). Minutes of aerobic exercise, strength exercise, fruit consumption, and vegetable consumption loaded together as expected on the second factor, Health Enhance (Table 4). Smoking, binge drinking and drinks per day loaded on a third factor, Health Reduce. Smoking loaded negatively on Overall Health and positively on Health Reduce. Despite this complex loading, Smoking was not dropped from subsequent models, given its strong relationship with health. Furthermore, because smoking is a behavior rather than a marker of health status, it was treated as such. Results provided preliminary support for the hypothesized three-factor model.

Major Analyses. The first SEM corresponded to the three-factor structure determined by the PCA (see Figure 1 for standardized coefficients). As expected with a large sample $(\mathrm{N}=209,172)$, chi square results indicated a significant difference between the proposed model and the data, $\chi^{2}(41)=$ $65225.690, p<.001$. Model fit indices approached but didn't meet acceptable ranges, AIC = 65143.690, $\mathrm{CFI}=0.840, \mathrm{MFI}=0.856, \mathrm{RMSEA}=0.087$ (90\% CI 0.087 to 0.088$)$, and $\mathrm{R}^{2}=0.145$. No parameters were recommended to be dropped. Inadmissible solutions were revealed via standardized regression parameters greater than 1.0 on Drink (Heywood, 1931). Heywood cases may indicate data-related problems including missing data, sample size, and misspecified models (Kolenikov et al., 2006). The alternate model was run, with the exogenous factors split into correlated but independent variables.

The alternative model (see Figure 2) revealed overall $\chi^{2}(23, \mathrm{~N}=209172)=24,526.162, p<.001$, with other indices indicating better fit than the previous model, $\mathrm{AIC}=24480.162, C F I=0.940, M F I=$ 0.943 , and $R M S E A=0.071$ (90\% CI 0.071 to 0.072 ). All path coefficients were statistically significant, 
RUNNINING HEAD: HEALTH BEHAVIOR MODELING

except for binge drinking. The amount of variance in Overall Health explained by the seven predictors was $R^{2}=.20$. Wald tests recommended dropping the path between Overall Health and binge drinking. LaGrange tests indicated that several exogenous variables were more clearly related to the endogenous Overall Health factor, especially the variable perceived health status. Therefore, an ad hoc model was analyzed with perceived health status as a mediating or linking variable between the separate behaviors and Overall Health.

The mediational model (see Figure 3) revealed $\chi^{2}(23, \mathrm{~N}=209,172)=21,598.619, p<.001$, with other fit indices indicating better fit than previous models, AIC $=21552.619, C F I=0.947, M F I=0.950$, and $R M S E A=0.067$ (90\% CI 0.066 to 0.068 ). All path coefficients were statistically significant. The amount of variance in Overall Health explained directly by perceived health status, and indirectly by the other six variables, was $R^{2}=0.443$. Wald tests did not indicate any extraneous parameters. LaGrange tests suggested additional pathways between exogenous variables and Overall Health variables such as Binge directly predicting Mental Health and Drink directly predicting PhysHlth; these were deemed redundant and not added. As the mediational model showed better signs of fit and better parsimony than previous models tested, it was selected as the final model. This model was then analyzed with the four individual states: Georgia, Massachusetts, Minnesota, and Utah (see Appendix). Some variability was noted in the path strength of the individual health variables, but each state showed similar excellent overall fit (Table 5). Multi-sample invariance testing revealed significant differences in overall chi squares. However, this was largely driven by sample size, both the overall size and differences in size between the national sample and the four individual states, all of various sizes. Other model fit indices indicated good overall fit with configural invariance, loading invariance, and parallel forms (see Appendix), providing further support of the final model.

\section{Discussion}

Using overlapping, rigorous methodologies, results from a large national sample revealed multiple health variables were linked with perceived health status, which in turn was linked with overall physical and mental health. Although there were slight differences in how specific health behaviors related, this same mediational model fit data reasonably well from four states from representative areas of the country (i.e., South: Georgia; Northeast: Massachusetts; Midwest: Minnesota; West: Utah), strengthening the generalizability of these results to American adults.

This study yielded several unexpected results. Binge drinking related negatively with perceived health status but did not significantly relate to Overall Health, possibly because Binge was dichotomized and its small effect was initially significant through sample size. Binge drinking may have been redundant when included alongside average alcohol consumption. Surprisingly, alcohol consumption positively 
RUNNINING HEAD: HEALTH BEHAVIOR MODELING

related to perceived health status and Overall Health. Alcohol consumption has been consistently linked to breast cancer, liver cirrhosis, hypertension, and alcohol dependence disorders (Rehm et al., 2003). One explanation may lie in the dataset's age-range. Younger age-groups (Knight et al., 2002; Naimi et al., 2003) show comparatively high rates of alcohol consumption and binge drinking. This age group also tends towards more robust health, as chronic illness is positively associated with age (NCI, 2015). Many medications for arthritis, hypertension, high cholesterol, etc. interact with alcohol and persons prescribed them avoid alcohol (NIAAA, 2014). A meta-analysis found regular low-volume alcohol consumption was not associated with health benefits over abstinence and occasional alcohol consumption (Stockwell et al., 2016). Because much of our sample was aged 65 or older and possibly was abstaining due to medication for age-driven chronic conditions. Future studies may examine whether positive benefits of alcohol remain constant across age, across abstainers, moderate, and heavy drinkers, and for healthy people vs. those suffering from chronic conditions.

Smoking related negatively with Overall Health, suggesting that smokers are experiencing the links between smoking and ill health Indeed tobacco is the leading cause of preventable death in the US (CDC, 2012; Mokdad et al., 2004). Former smokers outnumber current smokers in the US (Table 1) and many current smokers want to quit (Malarcher et al., 2011). Smoking loaded onto more than one factor, perhaps indicating that when contemplating how to improve their health, smoking cessation may be a key habit that merits changing.

Implications for Theory and Practice. This study examined-theoretical links between health behaviors and overall health. Whereas the PCA suggested alcohol consumption and smoking formed a health-reducing factor with exercise and fruit/vegetable consumption forming a health-enhancing factor, these results were not confirmed with SEM. Overall fit improved when variables linked individually with Overall Health, particularly when perceived health status served as a possible mediator. Some may argue these results confirm Newsom et al's (2005) finding that health behaviors showed minimal associations and therefore are relatively independent- However, although many inter-variable correlations were small, Wald tests never recommended dropping inter-variable paths. This indicates relationships between behaviors may be too complex for linear techniques and require nonparametric and/or non-linear analyses. The lack of health-reducing factor may be partially due to the small number of variables. Effect sizes, particularly in behavioral medicine tend to be small (Rossi, 2013), but small effects can have large population-level public health impacts (Prochaska et al., 2008).

Even if behaviors show small relatedness, the overall MHBC health benefits may still be greater than change in a single behavior. For example, smoking cessation, as part of an alcohol and drug addiction program, is associated with greater post-intervention sobriety (Prochaska, Delucchi \& Hall, 2004). Furthermore, while interventions targeting only one behavior often lead to greater change in that 
RUNNINING HEAD: HEALTH BEHAVIOR MODELING

behavior, MHBC interventions are often more effective in holistic health outcomes. For example, a diet/exercise intervention may cause less diet change than a diet-only intervention but the combined intervention may cause greater weight loss (Foster-Schubert et al., 2012; Sweet \& Fortier, 2010). Future research may clarify the relationships between health behaviors, perceived health, and health functioning.

Perceived health status linked relationships between health behaviors and overall health.

Although not hypothesized, the relationship between health perceptions and health behavior has been theoretically noted. The Health Belief Model (HBM) details why people do or don't engage in healthrelated behaviors (Becker, 1974). Two underlying dimensions are perceived susceptibility, how much a person believes their health is at risk, and perceived benefits, how much a person believes engaging in health-promoting behaviors will increase their general health or decrease the odds of illness. A HBM review revealed perceived susceptibility was strongly related to preventative-health behavior (Janz \& Becker, 1984), consistent with this study's finding that perceived health status, or perceived vulnerability to illness, can serve as a link between behavior and the outcome of behavior, overall health functioning. It is also possible that when considering their health, participants compared their current health to their past or desired future health. Future research should examine perceived health status and how it relates to people's decisions to engage in health-related behaviors.

MHBC-specific theories are currently limited. Noar, Chabot and Zimmerman (2008) suggested MHBC may be conceptualized as hierarchy with general health attitudes forming a superordinate category directing attitudes towards specific health behaviors, such as diet. Changes in general health attitudes theoretically lead to changes in attitudes towards specific health behaviors, and then to behavior changes. Our model indirectly supports this, by showing health behavior flows into general perceptions of health, which may influence health-related attitudes. MHBC interventions may operate by educating participants about linkages between health behaviors and health outcomes, helping them assess how their current behaviors impact their current or future health, and then taking steps on specific behaviors.

This study confirms findings that the most effective MHBC interventions focus on thematically related behaviors (Yin et al., 2013). Health-enhancing behaviors could have been conceptualized as "healthy weight" behaviors, and health-reducing behaviors as "addictive behaviors." Optimal number of behaviors has not been determined (Prochaska et al., 2006), but preliminary evidence suggests two behaviors may show better results than one or three (Wilson et al., 2015). Future studies may examine how many behaviors can load into given factors and whether the behaviors are better addressed within the same session (simultaneous intervention) or if the second behavior should be addressed only after sufficient progress on the first behavior (sequential intervention).

Limitations and Future Direction. This study has several limitations. Data were self-reported and not designed for SEM. Data largely relied on single-item measures, some showing nonnormality, and 
RUNNINING HEAD: HEALTH BEHAVIOR MODELING

much data were missing. Future studies could concentrate on individual states or use alternative sources, such as the NHANES nationally representative dataset which includes more detailed dietary recall questions and objective measures of overall health functioning, such as blood pressure.

This study concentrated on a few specific health behaviors. Other variables, such as sugar consumption and sleep, were considered, but too few states provided data for national estimations. Similarly, this study focused exclusively on behavioral health, rather than including metabolic or physiological biomarkers. Mentat health was included because physical and mental health are so closely intertwined (Kolappa, Henderson \& Kishore, 2013) and health behavior impacts both (Mujcic \& Oswald, 2016; Pendo \& Dahn, 2005)

It is reasonable to assume that general health is influenced by health-related behaviors. However, because this research studied cross-sectional data, causal conclusions cannot be inferred, nor can true mediation (MacKinnon, 2008; Maxwell \& Cole, 2007). Thus, our findings reflect a plausible pattern of associations and links, and not causal, mediational evidence. Longitudinal or experimental data are important to verify how MHBC causes changes in physical and mental health.

This study focused on the United States population as a whole. Different subpopulations have different health practices and habits. For example, men are more likely to exercise (CDC, 2013a), whereas women are more likely to eat healthily (Dehghan et al., 2011). A viable model may differ across subpopulations. Invariance testing should investigate consistency across gender, ethnicity, age, socioeconomic status, and health insurance.

To summarize, health behaviors significantly related to overall health, directly and indirectly through perceived health status. Health behavior is a large, complex construct, including such divergent variables as medication adherence, nightly sleep, UVA protection, and stress management. Even within "healthy diet," concepts such as saturated vs. unsaturated fat and sugar consumption weren't included in the current model; these variables are likely to interact. Whereas correlations between individual behaviors were relatively small, they were present and consistent. Future models should take into account more behaviors, and how they interact. 
RUNNINING HEAD: HEALTH BEHAVIOR MODELING

\section{References}

Allegrante, J. P., Peterson, J. C., Boutin-Foster, C., Ogedegbe, G., \& Charlson, M. E. (2008). Multiple health-risk behavior in a chronic disease population: what behaviors do people chose to change? Preventive Medicine, 46, 247-251.

Baer, H. J., Glynn, R. J., Hu, F. B., Hankinson, S. E., Willett, W. C., Colditz, G. A., Stampfer, M., \& Rosner, B. (2010). Risk factors for mortality in the Nurses' Health Study: A competing risks analysis. American Journal of Epidemiology, 173(3), 319-329.

Becker, M. H. (1974). The health belief model and personal health behavior. Health Education Monographs, 2, 324-508.

Bentler, P. M. (2006). EQS structural equations program manual. Encino, CA: Multivariate Software Inc.

Beran, T. N. \& Violato, C. (2010). Structural equation modeling in medical research: a primer. BioMed Central Research Notes, 3(1), 267.

Berrigan, D., Dodd, K., Troiano, R. P., Krebs-Smith, S. M., \& Barbash, R. B. (2003). Patterns of health behavior in U. S. adults. Preventive Medicine, 36, 615-623.

Blair, S. N., Horton, E., Leon, A. S., Lee, I., Drinkwater, B. L., Dishman, R. K., Mackey, M., \& Kienholz, M. L. (1996). Physical activity, nutrition and chronic disease. Medicine \& Science in Sports \& Exercise, 28(3), 335-349.

Cattell, R. B. (1966). The scree test for the number of factors. Multivariate Behavioral Research, 1, 245266.

Centers for Disease Control and Prevention (2012). Current cigarette smoking among adults-United States, 2011. Morbidity and Mortality Weekly Report, 61(44), 889-894.

Centers for Disease Control and Prevention (2013). Behavioral risk factor surveillance survey. Retrieved from http://www.cdc.gov/brfss/

Centers for Disease Control and Prevention (2015a). Adults meeting fruit and vegetable intake recommendations-United State, 2013. Morbidity and Mortality Weekly Report, 64(26), 709-713.

Centers for Disease Control and Prevention (2015b). How much physical activity do adults need? Division of Nutrition, Physical Activity, and Obesity. Updated June 4, 2015. Retrieved April 7, 2016. http://www.cdc.gov/physicalactivity/basics/adults/index.htm

Centers for Disease Control and Prevention (2017). National Center for Health Statistics. FastStats. Retrieved June 12, 2017 from https://www.cdc.gov/nchs/fastats/default.htm

Chiolero, A., Wietlisbach, V., Ruffieux, C., Paccaud, F., \& Cornuz, J. (2006). Clustering of risk behaviors with cigarette consumption: A population-based survey. Preventive Medicine, 42(5), 348-353. 
RUNNINING HEAD: HEALTH BEHAVIOR MODELING

Dehghan, M., Akhtar-Danesh, N., \& Merchant, A. T. (2011). Factors associated with fruit and vegetable consumption among adults. Journal of Human Nutrition and Dietetics, 24, 128-134.

Foster-Schubert, K. E., Alfano, C. M., Duggan, C. R., Xiao, L., Campbell, K. L., Kong, A., Bain, C. E., Wang, C., Blackburn, G. L., \& McTiernan, A. (2012). Effect of diet and exercise, alone or combined on weight and body composition in overweight-to-obese postmenopausal women. Obesity, 20, 1628-1638.

Graham, J. W. (2012). Missing data: Analysis and design. New York: Springer-Verlag.

Harlow, L. L. (2014). The essence of multivariate thinking ( $2^{\text {nd }} e d$.). New York, NY: Routledge

Heywood, H. B. (1931). On finite sequences of real numbers. Proceedings of the Royal Society of London. Series A Containing Papers of a Mathematical and Physical Character, 134(824), 486501 .

Hu, L., Bentler, P. M. (1999). Cutoff criteria for fit indexes in structure analysis: Conventional criteria versus new alternatives. Structural Equation Modeling, 6(1), 1-55.

Jackson, D. L., Gillaspy, J. A., \& Purc-Stephenson, R. (2009). Reporting practices in confirmatory factor analysis: an overview and some recommendations. Psychological Methods, 14(1), 6-23.

Janz, N. K., \& Becker, M. H. (1984). The health belief model: A decade later. Health Education Behavior, 11, 1-47.

Kanny, D., Liu, Y., Brewer, R. D., \& Lu, H. (2013). Binge drinking-United States, 2011. Morbidity and Mortality Weekly Report, 62(3), 77-80.

Kline, R B. (2016). Principles and practice of structural equation modeling (4th edition). New York, NY: Guilford Press.

Knight, J. R., Wechsler, H., Kuo, M., Seibring, M., Weitzman, E. R., \& Schuckit, M. A. (2002). Alcohol abuse and dependence among U.S. college students. Journal of Studies on Alcohol and Drugs, 63, 263-270.

Kolenikov, S., Bollen, K. A. \& Savalei, V. (2006, October). Specification tests with Heywood cases. In Proceedings of the American Statistical Association, Social Sciences Section.

Kolappa, K., Henderson, D. C., \& Kishore, S. P. (2013). No physical health without mental health: lessons unlearned? Bulletin of the World Health Organization, 91, 3-3A.

Lippke, S., Nigg, C. R., \& Maddock, J. E. (2012). Health-promoting and health-risk behaviors: Theorydriven analyses of multiple health behavior change in three international samples. International Journal of Behavioral Medicine, 19, 1-13.

MacKinnon, D. P. (2007). Introduction to statistical mediation analysis. New York, NY: Erlbaum.

Malarcher, A., Dube, S., Shaw, L., Babb, S., \& Kaufman, R. (2011). Quitting smoking among adultsUnited States, 2001-2010. Morbidity and Mortality Weekly Report, 60(44), 1513-1519. 
RUNNINING HEAD: HEALTH BEHAVIOR MODELING

Mathers, C. D. \& Loncar, D. (2006). Projections of global mortality and burden of disease from 2002 to 2030. PLOS Medicine, 3(11), 2011-2030.

Mawditt, C., Sackler, A., Britton, A., Kelly, Y. \& Cable, N. (2016). The clustering of health-related behaviours in a British population sample: Testing for cohort differences. Preventive Medicine, $88,95-107$.

Maxwell, S. E., \& Cole, D. A. (2007). Bias in cross-sectional analyses of longitudinal mediation. Psychological Methods, 12(1), 23-44.

McDonald, R. P. \& Ho, M. R. (2002). Principles and practices in reporting structural equation analyses. Psychological Methods, 7(1), 64-82.

Mokdad, A. H., Marks, J. S., Stroupe, D. F., \& Gerberding, J. L. (2004). Actual causes of death in the United States, 2000. Journal of the American Medical Association, 291(10), 1238-1245.

Mujcic, R. \& Oswald, A. J. (2016). Evolution of well-being and happiness after increases in consumption of fruit and vegetables. American Journal of Public Health, 106, 1504-1510.

Naimi, T. S., Brewer, R. D., Mokdad, A., Denny, C., Serdula, M. K., \& Marks, J. S. (2003). Binge drinking among US adults. Journal of the American Medical Association, 289, 70-75.

National Cancer Institute (2015). Causes and prevention: Age. About Cancer. Retrieved July 25, 2016 from http://www.cancer.gov/about-cancer/causes-prevention/risk/age

National Institute on Alcohol Abuse and Alcoholism (2014). Harmful interactions: Mixing alcohol with medications. Retrieved October 3, 2016 from http://pubs.niaaa.nih.gov/publications/Medicine/medicine.htm

National Research Council (1989). Diet and health: Implications for reducing chronic disease. Washington DC: National Academy Press.

Newsom, J. T., McFarland, B. H., Kaplan, M. S., Huguet, N., \& Zani, B. (2005). The health consciousness myth: Implications of the near independence of major health behaviors in the North American population. Social Science \& Medicine, 60, 433-437.

Noar, S. M., Chabot, M., \& Zimmerman, R. S. (2008). Applying health behavior theory to multiple behavior change: considerations and approaches. Preventive Medicine, 46, 275-280.

Paiva, A. L., Prochaska, J. O., Yin, H., Rossi, J. S., Redding, C. A., Blissmer, B., Robbins, M. L., Velicer, W. F., Lipschitz, J., Amoyal, N., Babbin, S. F., Blaney, C. L., Sillice, M. A., Fernandez, A., McGee, H. \& Horiuchi, S. (2012). Treated individuals who progress to action or maintenance for one behavior are more likely to make similar progress on another behavior: Coaction results of a pooled data analysis of three trials. Preventive Medicine, 54, 331-334.

Penedo, F. J., \& Dahn, J. R. (2005). Exercise and well-being: a review of mental and physical health benefits associated with physical activity. Current Opinion in Psychiatry, 18(2), 189-193. 
RUNNINING HEAD: HEALTH BEHAVIOR MODELING

Pierannunzi, C., Hu, S. S., \& Balluz, L. (2013). A systematic review of publications assessing reliability and validity of the Behavioral Risk Factor Surveillance Survey System (BRFSS), 2004-2011. BioMed Central Medical Research Methodology, 13, 49.

Prochaska, J. J., Delucchi, K., \& Hall, S. M. (2004). A meta-analysis of smoking cessation interventions in substance abuse treatment or recovery. Journal of Consulting and Clinical Psychology, 72, 1144-1156.

Prochaska, J. J., Spring, B., \& Nigg, (2008). Multiple health behavior change research: An introduction and overview. Preventive Medicine, 46(3), 181-188.

Prochaska, J. J., Velicer, W. F., Nigg, C. R., \& Prochaska, J. O. (2008). Methods of quantifying change in multiple risk factor interventions. Preventive Medicine, 46, 260-265.

Rehm, J., Room, R., Graham, K., Monteiro, M., Gmel, G., \& Sempos, C. T. (2003). The relationship of average volume of alcohol consumption and patterns of drinking to burden of disease: an overview. Addiction, 98, 1209-1228.

Rossi, J. S. (2013). Statistical power analysis. In J. A. Schinka \& W. F. Velicer (eds.). Handbook of psychology, Volume 2: Research methods in psychology (2 $2^{\text {nd }}$ ed.) (pp. 71-108). New York, NY: John Wiley \& Sons.

Stockwell, T., Zhao, J., Panwar, S., Roemer, A., Naimi, T., \& Chikritzhs, T. (2016). Do "moderate" drinkers have reduced mortality risk? A systematic review and meta-analysis of alcohol consumption and all-cause mortality. Journal of Studies on Alcohol and Drugs, 77, 185-198.

Spring, B., Moller, A. C., \& Coons, M. J. (2012). Multiple health behaviours: overview and implications. Journal of Public Health, 34(S1), i3-110.

Sweet, S. N. \& Fortier, M. S. (2010). Improving physical activity and dietary behaviors with single or multiple health behavior interventions? A synthesis of meta-analyses and reviews. International Journal of Environmental Research and Public Health, 7, 1720-1743.

US Department of Agriculture (2016). Dietary Guidelines 2015-2020: Appendix 1. Physical Activity Guidelines for Americans. Retrieved April 7, 2016. http://health.gov/dietaryguidelines/2015/guidelines/appendix-1/

U.S. Department of Health and Human Services (1991). Healthy people 2000: National health promotion and disease prevention objectives. DHHS Publication No. (PHS) 91-50212. Washington DC: U.S. Government Printing Office.

U.S. Depts. of Health and Human Services and of Agriculture (2015). 2015-2020 Dietary Guidelines for Americans. $8^{\text {th }}$ Edition. Retrieved from http://health.gov/dietaryguidelines/2015/guidelines/.

Yin, H., Prochaska, J. O., Rossi, J. S., Redding, C. A., Paiva, A. L., Blissmer, B., Velicer, W. F., Johnson, S. S. \& Kobayashi, H. (2013). Treatment-enhanced paired action contributions substantially to 
RUNNINING HEAD: HEALTH BEHAVIOR MODELING

change across multiple health behaviors: secondary analyses of five randomized trials.

Translational Behavioral Medicine, 3, 62-71. 
RUNNINING HEAD: HEALTH BEHAVIOR MODELING

Table 1: Basic Demographic Information on the Sample

\begin{tabular}{llll}
\hline Variable & Group & Frequency & Percentage \\
\hline Age & 18 to 24 years & 23069 & 4.6 \\
& 25 to 34 years & 49621 & 9.8 \\
& 35 to 44 years & 65487 & 12.9 \\
& 45 to 54 years & 92177 & 18.2 \\
& 55 to 64 years & 115569 & 22.8 \\
& 65 years or older & 160544 & 31.7 \\
\hline Education completed & Less than high school & 46423 & 9.2 \\
& High school & 149387 & 29.5 \\
& Some college/tech school & 136060 & 26.9 \\
& College/tech school & 172669 & 34.1 \\
\hline Marital Status & Married & 268086 & 52.9 \\
& Divorced & 71211 & 14.1 \\
& Widowed & 69887 & 13.8 \\
& Separated & 11081 & 2.2 \\
& Never Married & 70738 & 14.0 \\
& Unmarried Couple & 12837 & 2.5 \\
\hline Race & White & 391068 & 77.2 \\
& Black & 40613 & 8.0 \\
& Other (non-Hispanic) & 20942 & 4.1 \\
& Multiracial & 9011 & 1.8 \\
& Hispanic & 38718 & 7.6 \\
\hline
\end{tabular}


RUNNINING HEAD: HEALTH BEHAVIOR MODELING

Table 2: Descriptive Statistics of Main Study Variables

\begin{tabular}{|c|c|c|c|c|c|c|c|}
\hline \multicolumn{8}{|l|}{ Variables } \\
\hline Perchlth & 504455 & 1.00 & 5.00 & 3.4157 & 1.10494 & -.351 & -.519 \\
\hline Physhlth & 494280 & 1.00 & 31.00 & 26.6443 & 8.86699 & -2.153 & 3.225 \\
\hline Menthlth & 496702 & 1.00 & 31.00 & 27.5329 & 7.79784 & -2.549 & 5.393 \\
\hline Activity & 257522 & 1.00 & 31.00 & 25.7922 & 9.35336 & -1.829 & 1.931 \\
\hline Veg & 466693 & .00 & 23.00 & 1.9133 & 1.28313 & 2.236 & 12.209 \\
\hline Strength & 477662 & 1.00 & 2.00 & 1.2601 & .43869 & 1.094 & -.804 \\
\hline Fruit & 473304 & .00 & 16.00 & 1.4616 & 1.21272 & 1.877 & 7.137 \\
\hline Drink & 469177 & .00 & 16.67 & .3770 & .88585 & 5.812 & 54.360 \\
\hline Log Drink & 469177 & -2.00 & 1.22 & -1.2119 & .86786 & .516 & -1.227 \\
\hline \multicolumn{2}{|c|}{ Categorical Variables } & \multicolumn{2}{|c|}{ Group } & \multicolumn{2}{|l|}{ Frequency } & \multicolumn{2}{|l|}{ Percentage } \\
\hline \multirow{3}{*}{\multicolumn{2}{|c|}{ PA 150}} & \multicolumn{2}{|c|}{ Zero Minutes } & \multicolumn{2}{|l|}{134785} & \multicolumn{2}{|l|}{28.9} \\
\hline & & \multicolumn{2}{|c|}{ 1-149 Minutes } & \multicolumn{2}{|l|}{89049} & \multicolumn{2}{|l|}{19.1} \\
\hline & & \multicolumn{2}{|c|}{150 Minutes or More } & \multicolumn{2}{|l|}{242482} & \multicolumn{2}{|l|}{52.0} \\
\hline \multirow{4}{*}{\multicolumn{2}{|c|}{ Smoke }} & \multicolumn{2}{|c|}{ Never Smoked } & \multicolumn{2}{|l|}{271310} & \multicolumn{2}{|l|}{53.6} \\
\hline & & \multicolumn{2}{|c|}{ Former Smoker } & \multicolumn{2}{|l|}{147864} & \multicolumn{2}{|l|}{29.2} \\
\hline & & \multicolumn{2}{|c|}{ Smokes some days } & \multicolumn{2}{|l|}{22724} & \multicolumn{2}{|l|}{4.5} \\
\hline & & \multicolumn{2}{|c|}{ Smokes every day } & \multicolumn{2}{|l|}{62027} & \multicolumn{2}{|l|}{12.2} \\
\hline \multirow[t]{3}{*}{ Binge } & & \multicolumn{2}{|l|}{ No } & \multicolumn{2}{|l|}{408889} & \multicolumn{2}{|l|}{80.7} \\
\hline & & \multicolumn{2}{|l|}{ Yes } & \multicolumn{2}{|l|}{60769} & \multicolumn{2}{|l|}{12.0} \\
\hline & & Not $\mathrm{G}$ & & 36809 & & 7.3 & \\
\hline
\end{tabular}

Note. Perchlth $=$ Perceived general health status; Physlth $=$ number of days in the past month with good physical health; Menthlth = number of days in the past month with good mental health; Activity = number of days in the past month able to do usual activities without health-related problems; Veg = total consumption of vegetables per day in the past month; Strength = Meets strength guidelines (yes / no); Fruit $=$ total consumption of fruits per day in the past month; Drink = Average number of alcoholic drinks per day; PA150 = minutes aerobic exercise per week (zero; $1-149 ; 150$ or more); Smoke $=$ Smoking categories (Never smoker; former smoker, smokes some days, smokes every day); Binge = Binge drinking status (not a binge drinker vs. binge drinker. 
RUNNINING HEAD: HEALTH BEHAVIOR MODELING

Table 3

Promax Rotated Principle Component Analysis Results, Complete Cases Only, allowing factors to vary

\begin{tabular}{lccc}
\hline & 1 & 2 & 3 \\
\hline Perchlth & .714 & .114 & .108 \\
Physhlth & .800 & .090 & -.078 \\
Menthlth & .549 & -.223 & -.019 \\
Activity & .835 & -.027 & -.114 \\
Veg & -.101 & -.017 & .760 \\
Strength & .005 & .158 & .519 \\
Fruit & -.097 & -.142 & .758 \\
PA150 & .250 & .135 & .456 \\
Smoke & -.375 & .445 & -.169 \\
Drink & .096 & .815 & .093 \\
Binge & -.046 & .849 & -.004 \\
\hline Eigenvalue & 2.669 & 1.655 & 1.426 \\
Percentage & 24.267 & 15.046 & 12.960 \\
Accounted & & & \\
Cumulative & 24.267 & 39.313 & 52.273 \\
Percentage & & & \\
\hline
\end{tabular}

Note. Perchlth $=$ Perceived general health status; Physlth = number of days in the past month with good physical health; Menthlth = number of days in the past month with good mental health; Activity = number of days in the past month able to do usual activities without health-related problems; Veg = total consumption of vegetables per day in the past month; Strength = Meets strength guidelines (yes / no); Fruit $=$ total consumption of fruits per day in the past month; PA150 = minutes aerobic exercise per week (zero, 1-149, 150 or more); Smoke = Smoking categories (Never smoker; , former smoker, smokes some days, smokes every day); Drink = Average number of alcoholic drinks per day; Binge $=$ Binge drinking status (not a binge drinker vs. binge drinker).

Boldface italics indicates salient variable loadings on their respective factor(s). 
Table 4

Correlations between Main Study Variables

\begin{tabular}{lrrrrrrrrrr}
\hline & Physhlth & Menthlth & Activity & Veg & Strength & Fruit & PA150 & Smoke & Drink & Binge \\
\hline Perchlth & $.525^{* *}$ & $.289^{* *}$ & $.432^{* *}$ & $.131^{* *}$ & $.177^{* *}$ & $.102^{* *}$ & $.266^{* *}$ & $-.165^{* *}$ & $.223^{* *}$ & $.076^{* *}$ \\
Physhlth & 1 & $.346^{* *}$ & $.574^{* *}$ & $.053^{* *}$ & $.072^{* *}$ &. $.035^{* *}$ & $.204^{* *}$ & $-.120^{* *}$ & $.154^{* *}$ & $.065^{* *}$ \\
Menthlth & $.346^{* *}$ & 1 & $.330^{* *}$ & $.051^{* *}$ & $.051^{* *}$ & $.061^{* *}$ & $.111^{* *}$ & $-.163^{* *}$ & $.046^{* *}$ & $-.025^{* *}$ \\
Activity & $.574^{* *}$ & $.330^{* *}$ & 1 & $.048^{* *}$ & $.060^{* *}$ & $.032^{* *}$ & $.205^{* *}$ & $-.136^{* *}$ & $.153^{* *}$ & $.070^{* *}$ \\
Veg & $.053^{* *}$ & $.051^{* *}$ & $.048^{* *}$ & 1 & $.154^{* *}$ & $.398^{* *}$ & $.182^{* *}$ & $-.083^{* *}$ & $.050^{* *}$ & $-.024^{* *}$ \\
Strength & $.072^{* *}$ & $.051^{* *}$ & $.060^{* *}$ & $.154^{* *}$ & 1 & $.146^{* *}$ & $.257^{* *}$ & $-.069^{* *}$ & $.117^{* *}$ & $.052^{* *}$ \\
Fruit & $.035^{* *}$ & $.061^{* *}$ & $.032^{* *}$ & $.398^{* *}$ & $.146^{* *}$ & 1 & $.172^{* *}$ & $-.136^{* *}$ & $-.017^{* *}$ & $-.072^{* *}$ \\
PA150 & $.204^{* *}$ & $.111^{* *}$ & $.205^{* *}$ & $.182^{* *}$ & $.257^{* *}$ & $.172^{* *}$ & 1 & $-.095^{* *}$ & $.154^{* *}$ & $.040^{* *}$ \\
Smoke & $-.120^{* *}$ & $-.163^{* *}$ & $-.136^{* *}$ & $-.083^{* *}$ & $-.069^{* *}$ & $-.136^{* *}$ & $-.095^{* *}$ & 1 & $.105^{* *}$ & $.154^{* *}$ \\
Drink & $.154^{* *}$ & $.046^{* *}$ & $.153^{* *}$ & $.050^{* *}$ & $.117^{* *}$ & $-.017^{* *}$ & $.154^{* *}$ & $.105^{* *}$ & 1 & $.540^{* *}$ \\
Binge & $.065^{* *}$ & $-.025^{* *}$ & $.070^{* *}$ & $-.024^{* *}$ & $.052^{* *}$ & $-.072^{* *}$ & $.040^{* *}$ & $.154^{* *}$ & $.540^{* *}$ & 1 \\
\hline
\end{tabular}

$* * \mathrm{p}<.001$

Note Perchlth $=$ Perceived general health status; Physlth $=$ number of days in the past month with good physical health; Menthlth $=$ number of days in the past month with good mental health; Activity = number of days in the past month able to do usual activities without health-related problems; Veg = total consumption of vegetables per day in the past month; Strength = Meets strength guidelines (yes / no); Fruit = total consumption of fruits per day in the past month; PA150 = minutes aerobic exercise per week (zero; 1-149; 150 or more); Smoke = Smoking categories (Never smoker; former smoker, smokes some days, smokes every day); Drink = Average number of alcoholic drinks per day; Binge = Binge drinking status (not a binge drinker vs. binge drinker). 
RUNNINING HEAD: HEALTH BEHAVIOR MODELING

Table 5

Standardized pathways between variables by overall model and state in final model

\begin{tabular}{lccccc}
\hline Variable Paths & All & GA & MA & MN & UT \\
\hline Veg > Perchlth & $.048^{*}$ & $.068^{*}$ & $.080^{*}$ & $.061^{*}$ & $.030^{*}$ \\
Strength > Perchlth & $.077^{*}$ & $.072^{*}$ & $.062^{*}$ & $.063^{*}$ & $.084^{*}$ \\
Fruit > Perchlth & $.012^{*}$ & -0.023 & .002 & $.040^{*}$ & $.030^{*}$ \\
PA150 > Perchlth & $.196^{*}$ & $.206^{*}$ & $.193^{*}$ & $.172^{*}$ & $.207^{*}$ \\
Smoke > Perchlth & $-.166^{*}$ & $-.174^{*}$ & $-.157^{*}$ & $-.151^{*}$ & $-.201^{*}$ \\
Drink > Perchlth & $.239^{*}$ & $.236^{*}$ & $.252^{*}$ & $.215^{*}$ & $.081^{*}$ \\
Binge > Perchlth & $-.013^{*}$ & .027 & -.003 & $-.033^{*}$ & .014 \\
& & & & & \\
\hline Perchlth > Overall Health & $.665^{*}$ & $.659^{*}$ & $.641^{*}$ & $.629^{*}$ & $.642^{*}$ \\
& & & & & \\
\hline Overall Health > Physhlth & $.803^{*}$ & $.804^{*}$ & $.810^{*}$ & $.800^{*}$ & $.800^{*}$ \\
Overall Health > Menthlth & $.308^{*}$ & $.330^{*}$ & $.315^{*}$ & $.311^{*}$ & $.358^{*}$ \\
Overall Health > Activity & .715 & .716 & .702 & .746 & .751
\end{tabular}

$* \mathrm{p}<.05$

Note 1 . The unstandardized pathway to Activity was initially set to 1.0 in each model.

Note 2. Perchlth = Perceived general health status; Physlth = number of days in the past month with good physical health; Menthlth = number of days in the past month with good mental health; Activity = number of days in the past month able to do usual activities without health-related problems; Fruit = total consumption of fruits per day in the past month; $\mathrm{Veg}=$ total consumption of vegetables per day in the past month; $\mathrm{PA}=$ minutes per week of total physical activity/exercise; Strength $=$ Number of time per week engaging in exercise designed to strengthen muscles; PAcat = Physical activity category (inactive, insufficiently active, active, highly active); Smoke = Smoking categories (Never smoker; former smoker, smokes some days, smokes every day); Binge = Binge drinking status (not a binge drinker vs. binge drinker); Drink = Average number of alcoholic drinks per day. 
RUNNINING HEAD: HEALTH BEHAVIOR MODELING

Appendix

Table A1. Overall Model fit by state

\begin{tabular}{|l|c|c|c|c|c|c|c|c|c|}
\hline State & $\mathrm{N}$ & $\chi^{2}$ & $\mathrm{df}$ & AIC & CFI & MFI & RMSEA & $90 \%$ CI & $\mathrm{R}^{2}$ Factor \\
& & & & & & & & & \\
\hline Georgia & 3784 & $463.173^{*}$ & 23 & 417.173 & 0.941 & 0.943 & 0.071 & $0.066,0.077$ & .434 \\
\hline Massachusetts & 8693 & $960.304^{*}$ & 23 & 914.304 & 0.943 & 0.948 & 0.068 & $0.065,0.072$ & .410 \\
\hline Minnesota & 6039 & $544.548^{*}$ & 23 & 495.723 & 0.954 & 0.958 & 0.061 & $0.057,0.066$ & .395 \\
\hline Utah & 5721 & $627.727^{*}$ & 23 & 581.727 & 0.954 & 0.949 & 0.068 & $0.063,0.072$ & .413 \\
\hline
\end{tabular}

$* p<0.01$ 
RUNNINING HEAD: HEALTH BEHAVIOR MODELING

Table A2. Invariance Testing of Final Model

\begin{tabular}{lcccccc}
\hline Model Invariance & $\chi^{2}$ & df & CFI & MFI & RMSEA & $90 \%$ CI \\
\hline Configural Invariance & $2596^{*}$ & 92 & .948 & .950 & 0.067 & $0.065,0.069$ \\
Loading Invariance & $2604^{*}$ & 98 & .948 & .950 & 0.065 & $0.063,0.067$ \\
Parallel Forms & 3320 & 113 & 0.934 & 0.936 & 0.068 & $0.066,0.070$ \\
& & & & & & \\
\hline
\end{tabular}

$* p<0.01$ 